\title{
Knowledge on National Free Health Services among Preclinical Medical Students
}

\author{
Hari Prasad Upadhyay, ${ }^{1}$ Neeti Prasai, ${ }^{2}$ Meera Prasai, ${ }^{1}$ Prativa Sedai, ${ }^{3}$ Sirjana Panthi ${ }^{1}$ \\ ${ }^{1}$ Department of Community Medicine, College of Medical Sciences-Teaching Hospital, Bharatpur, Chitwan, Nepal, \\ ${ }^{2}$ Sundar Bazar Hospital, Lamjung, Nepal, ${ }^{3}$ Department of ENT, B.P. Koirala Memorial Cancer Hospital, Bharatpur, \\ Chitwan, Nepal.
}

\begin{abstract}
Background: National free health services are those facilities which are given by the government in free of cost for all the citizens in specific countries. Free health service program provides essential health care services free of charge to all users at Primary Health Care Centers, Health Posts. Methods: A cross-sectional analytical study was conducted among 395 preclinical medical students Bharatpur, Chitwan, Nepal by using non probability sampling technique. In the Bivariate analysis, Chi-square test was done. Before the binary logistic regression Multicollinearity of independent variables was check by using Variance inflation factor (VIF). Binary logistic regression was performed to examine the net effect of each independent variable on the Dependent variable. Results: Result showed that $24.8 \%$ students had good knowledge on national free health services (with 95\% CI $20.81 \%$ to 29.3\%). The overall level of knowledge of BPH students had good followed by nursing students. Students who were in the age group 20-25 years had 3.54 times (with $95 \%$ CI for $\mathrm{OR}=1.869$ to 6.689) as compared 15-20 years and students of age 25-30 years had 14.04 times (with $95 \%$ CI for OR $=5.292$ to 37.262 ) good knowledge as compare to those who were in the age group 15-20 years. Female students had 2 times (with $95 \% \mathrm{CI}$ for $\mathrm{OR}=1.002$ to 3.977) good knowledge as compare to male students. Students who were from BDS had 0.83 times (with $95 \%$ CI for OR $=0.159$ to 4.319), students who were from Nursing had 1.70 times (with $95 \%$ CI for OR $=0.658$ to 4.402 ), students who were from $\mathrm{BPH}$ had 4.34 times (with $95 \% \mathrm{CI}$ for OR $=1.698$ to 11.087 ) and students who were from B Pharmacy had 1.10 times (with $95 \%$ CI for OR $=0.415$ to 2.941 ) times higher odds of knowledge as compare to those students who were from MBBS. Conclusions: The overall level of knowledge among the preclinical medical students is poor; only one fourth students had good level of knowledge. Majority of the students don't know name of the basic free health services provided by government of Nepal. Students of younger adult had good knowledge. BHP and Nursing students had good knowledge as compared to other level. Statistically significant variable with level of knowledge are age ( $p$-value $<0.001)$, gender ( $p$-value 0.049 ), level of education ( $p$-value $<0.001$ ).
\end{abstract}

Keywords: age; education level; free health services; gender; preclinical medical students.

\section{INTRODUCTION}

Health care means the prevention, treatment and management of illness and preservation of mental and physical well being through the services offered by the medical and allied health professions. It is influenced by a number of factors and processes: technical, financial and political. ${ }^{1}$ National free health services are those facilities which are given by the government in free of cost for all the citizens in specific countries. Choice of health care facilities depends on both the features of the facilities such as area of expertise, level of care, cost and quality and the characteristics of patients including economic status, health status, education and gender. ${ }^{2}$ Free health service program provides essential health care services free of charge to all users at Primary Health Care Centers, Health Posts. ${ }^{3}$ Similarly, outpatient, inpatient, emergency services and essential drugs are provided free for targeted groups viz. poor, ultra-poor, senior citizens, disabled, and Female Community Health Volunteers, and only listed essential drugs for all users in up to 25 bedded district hospitals.

Nepal's Interim Constitution 2007 addresses health as a fundamental right and that every citizen shall have the right to basic health services free of cost from the state, as provided in law. Basic health services was started with the slogan "New Nepal, Healthy Nepal" by the government in January 2009 mentioned that all citizen are able to access district hospital and primary health care centre (PHC) without having to pay for registration. Further, to pursue a policy of establishing the rights of all citizens to health has

Correspondence: Mr. Hari Prasad Upadhyay, Department of Community Medicine, College of Medical Sciences Teaching Hospital, Bharatpur, Chitwan, Nepal. Email: hpchalise@gmail.com. Phone: +977-9855058464. Article received: 2019-03-05. Article accepted: 2019-06-1. 
been regarded as one of the responsibilities of the state. The constitutional provision has set the platform for commencement of free health service program in Nepal. Nepal subsequently abolished user fees on primary health care services to reduce inequalities in access to and use of health services and in health outcomes. ${ }^{5}$ Under the free health programme, National Immunization, Nutrition is mainly related with child health. Safe motherhood, female community health volunteer program, primary health care outreach comes under Family health. Aama programme under safe mother hood was launched to increase institutional delivery and to reduce cost of delivery. Program provides cash payment who deliver in health facilities according to ecological region, incentive payment for health worker and recently 1000 public health institution are providing Aama program. ${ }^{6}$ Besides that free treatment and laboratory services for disease like Tuberculosis, Leprosy, Malaria, Kalazar are also available for the people. Primary health care revitalization has increased the essential drug items (40-70) which also include some of the non communicable diseases. ${ }^{7}$

Government of Nepal has introduced New National Health Policy 2014 replacing the two decades old National Health Policy 1991. The new policy has devised different strategies to effectively implement Universal Health Coverage and provide free basic health services. ${ }^{5}$ In Nepal in order to increase the converge of health care services, a voluntary program to National health insurance programmed is adopted from 2014 to provide special protection to poor and marginalized people. ${ }^{7}$ To increase the coverage of national free health care services, awareness program and information regarding free health care programme is being delivered by different social media, broadcast through television and $\mathrm{Fm}$ radios. Due to various factors the knowledge and use of services by people is not much known. The knowledge on availability of free health care services was found to be $76.2 \%$ in Neapl. ${ }^{8}$ The number of people visiting hospitals for free health services is increasing in Kathmandu valley and increasing trend is observed in other part of Nepal also, but there are still many people who do not know about the free health services provided by the government. ${ }^{9}$

Evidence from other low-income countries showed that provision of free health service increases its use. ${ }^{10}$ Medical students are the future pillar to make the healthy nation, they are the key persons to circulate and give good message to the people. Few hour teaching about Nepal Health policy is there in preclinical courses. The aim of the study is to assess the level of knowledge of students on National Free Health care and to find the significant factors among the preclinical medical students.
METHODS

A cross-sectional analytical study was conducted among 395 students MBBS, BDS, BPH, B.Pharmacy and B.Nursing students of College of Medical Sciences and Shree Medical \& Technical College of Bharatpur, Chitwan, Nepal from June 2019 to July 2019. Reliability and validity of self designed questionnaire was determined using pilot study among $10 \%$ of total sample size. In SPSS-20 Cronbach's alpha was calculated, it value was 0.719 . Then consulting other expertise in this area questionnaire was finalized. Then this wellstructured questionnaire was distributed among students using non probability sampling technique (Convenient sampling). By taking unknown prevalence $(\mathrm{p}=50 \%$ and $\mathrm{q}=50 \%), 5 \%$ level of significance (The z-score value at $95 \%$ Confidence interval is 1.96) and with 5\% margin of error. Sample size was determined by using the formula $(\mathrm{n})=\mathrm{Z}^{2} \mathrm{pq} / \mathrm{e}^{2}=(1.96 * 1.96 * 0.50 * 0.50) /(0.05 * 0.05)=$ 384. The optimum sample size for required for this study was 384 but study was conducted among 395 students. Ethical approval was taken from Institutional Review Committee of College of Medical Sciences. At the time of data collection verbal consent with signature was taken from all students. Collected data was check for completeness and then coded with numbering. Then data was entered in EpiData 3.1. analysis, to test the significance of association between dependent variable (level of knowledge) and independent variables, Chi-square test was done. Variance inflation factor (VIF) was used to check the Multicollinearity of independent variables which were statistically significant in Bivariate anlaysis. Only for those variables which were statistically significant in Bivariate analysis for them Binary logistic regression was performed to examine the net effect of each independent variable on the Dependent variable. Odds ratio and its 95\% confidence interval was calculated. The accuracy of fitted Binary logistic regression was done by using Hosmer- Lemeshow test statistic. P-values less than 0.05 were considered as statistically significant.

\section{RESULTS}

The response of 395 students was collected. Finding showed majority of the students were in the age group 20-25 years and least were in the age group 25-30 years. The mean \pm SD of age was $21.44 \pm 2.44$ years. Majority of the respondents were female $(69.4 \%)$ by gender and urban $(86.6 \%)$ by place of residence. Regarding the level of education $32.9 \%$ students were from Nursing, 20\% B Pharmacy and least were from BDS. Majority of the respondents were Hindu $(90.9 \%)$ by religion and Brahmin $(52.2 \%)$ by ethnicity. Regarding socioeconomic status, majority of the students were from upper middle class II (61\%), lower middle 
class $(18.2 \%)$ and least were from upper lower class IV (Table 1).

\begin{tabular}{|c|c|c|}
\hline \multicolumn{3}{|c|}{$\begin{array}{l}\text { Table 1. Sociodemographic Characteristics of the } \\
\text { Respondents. }(n=395)\end{array}$} \\
\hline Characteristics & Number & Percentage \\
\hline \multicolumn{3}{|l|}{ Age } \\
\hline $15-20$ & 170 & 43 \\
\hline $20-25$ & 195 & 49.4 \\
\hline $25-30$ & 30 & 7.6 \\
\hline Mean \pm SD & \multicolumn{2}{|c|}{$21.44 \pm 2.44$ years } \\
\hline \multicolumn{3}{|l|}{ Gender } \\
\hline Male & 121 & 30.6 \\
\hline Female & 274 & 69.4 \\
\hline \multicolumn{3}{|l|}{ Address } \\
\hline Urban & 342 & 86.6 \\
\hline Rural & 53 & 13.4 \\
\hline \multicolumn{3}{|l|}{ Level of education } \\
\hline MBBS & 93 & 23.5 \\
\hline BDS & 25 & 6.3 \\
\hline Nursing & 130 & 32.9 \\
\hline $\mathrm{BPH}$ & 65 & 16.5 \\
\hline B Pharmacy & 82 & 20.8 \\
\hline \multicolumn{3}{|l|}{ Religion } \\
\hline Hindu & 359 & 90.9 \\
\hline Buddhist & 25 & 6.3 \\
\hline Christian & 6 & 1.5 \\
\hline Muslim & 4 & 1 \\
\hline Others & 1 & 0.3 \\
\hline \multicolumn{3}{|l|}{ Ethnicity } \\
\hline Brahmin & 206 & 52.2 \\
\hline Chhettri & 73 & 18.5 \\
\hline \multicolumn{3}{|l|}{ Dalit/Janajati/Gurung/ } \\
\hline Others (Shah, Teli) & 26 & 6.6 \\
\hline \multicolumn{3}{|c|}{ Socioeconomic status (Kuppuswamy Scale) } \\
\hline Upper I & 66 & 16.7 \\
\hline Upper Middle class II & 241 & 61 \\
\hline Lower Middle class III & 72 & 18.2 \\
\hline Upper Lower class IV & 16 & 4.1 \\
\hline
\end{tabular}

Regarding the knowledge on each components of question, nearly half $(42.03 \%)$ of the students know the meaning of free health services. Only $11.39 \%$ of the students know the name of different health care program provided in Nepal. Nearly one fourth $(23.04 \%)$ students know the number of vaccine available at free of cost in Nepal. Very few $(6.90 \%)$ students know the name of dangerous disease for which government has given some found for the treatment. More than $70 \%$ students know the amount of fund given by government for the treatments of disease. Also, one third (34.94\%) students know the number of medicine given free of cost in Government health institution. Nearly half of the students know the amount of money to register in National health insurance system. Nearly $70 \%$ student knows the minimum distance (30 minutes) to access basic health services to people. More than half of the students know the name of frontline volunteer of community who provide health services and linked community to the health institution. Very few $(4.30 \%)$ of the students know all the name of disease for which treatment is given free of cost by government of Nepal. Only one third $(31.65 \%)$ students know the name of clinic at health institution from where the medicine of tuberculosis is given. Also, $8.10 \%$ students know the component of safe Motherhood and Newborn health program.

More than $75 \%$ students know the incentive given to the mother when delivery is conducted on health institution. Only (7.79\%) students know the activities comes under Nutrition program. More than $40 \%$ students know the name of health worker who support in home delivery and encourage to apply Chlorhexidine to the umbilicus of new born child (Table 2).

\begin{tabular}{|c|c|c|}
\hline Questions & Number & $\%$ \\
\hline Meaning of free health service & 166 & 42.03 \\
\hline $\begin{array}{l}\text { Name of different health free care } \\
\text { program (all) }\end{array}$ & 45 & 11.39 \\
\hline $\begin{array}{l}\text { Number of vaccine available at } \\
\text { free of cost }\end{array}$ & 91 & 23.04 \\
\hline $\begin{array}{l}\text { Dangerous disease for which gov- } \\
\text { ernment has given some fund }\end{array}$ & 28 & 6.9 \\
\hline $\begin{array}{l}\text { Amount of found given by gov- } \\
\text { ernment for the treatment of dan- } \\
\text { gerous disease }\end{array}$ & 287 & 72.66 \\
\hline $\begin{array}{l}\text { Number of medicine given free of } \\
\text { cost in health institution }\end{array}$ & 138 & 34.94 \\
\hline $\begin{array}{l}\text { Amount of money has to be de- } \\
\text { posit in NHI per year }\end{array}$ & 171 & 43.29 \\
\hline $\begin{array}{l}\text { The minimum distance of accessi- } \\
\text { bility of basic health services to } \\
\text { people }\end{array}$ & 267 & 67.59 \\
\hline $\begin{array}{l}\text { Frontline volunteer of community } \\
\text { to provide health services and } \\
\text { linked community to the health } \\
\text { institution }\end{array}$ & 207 & 52.41 \\
\hline $\begin{array}{l}\text { Name of disease for which treat- } \\
\text { ment is given free of cost }\end{array}$ & 17 & 4.3 \\
\hline $\begin{array}{l}\text { Name of clinic at health institu- } \\
\text { tion from where the medicine of } \\
\text { tuberculosis is given }\end{array}$ & 125 & 31.65 \\
\hline $\begin{array}{l}\text { Component of safe Motherhood } \\
\text { and Newborn health program }\end{array}$ & 32 & 8.1 \\
\hline $\begin{array}{l}\text { Incentive given to the mother } \\
\text { when delivery is conducted on } \\
\text { health institution }\end{array}$ & 298 & 75.44 \\
\hline $\begin{array}{l}\text { Activities comes under Nutrition } \\
\text { program }\end{array}$ & 30 & 7.59 \\
\hline $\begin{array}{l}\text { Support in home delivery and } \\
\text { encourage to apply Chlorhexidine } \\
\text { to the umbilicus of new born } \\
\text { child }\end{array}$ & 169 & 42.78 \\
\hline
\end{tabular}

Our research showed that only $24.8 \%$ students had good knowledge on national free health services and the $95 \%$ confidence interval of good 
Upadhyay et al. Knowledge on National Free Health Services among Preclinical Medical..

knowledge is $20.81 \%$ to $29.3 \%$. This is shown in the following (Table 3).

\begin{tabular}{|lcccc|}
\hline \multicolumn{4}{|l|}{$\begin{array}{l}\text { Table 3. Overall Level of Knowledge on National } \\
\text { Free Health Service. (n=395) }\end{array}$} & \\
\hline $\begin{array}{l}\text { Level of } \\
\text { Knowledge }\end{array}$ & Frequency & Percent & 95\% CI \\
Good & 98 & 24.8 & 20.81 & 29.3 \\
Poor & 297 & 75.2 & & \\
\hline
\end{tabular}

Regarding the level of knowledge, the students who were in the age group 25 to 30 had good knowledge and least was in the age group 15 to 20 years. Female students had good knowledge as compare to the male students.

Students from urban area had good knowledge as compare to rural areas students. The level of knowledge is high among the BPH students followed by Nursing students and least were among BDS students. Regarding the religion Christian students had good knowledge. In response to ethnicity chhettri had good level of knowledge. Students of upper middle class II had good level followed by lower middle class III. The overall statistically significant variables to the level of knowledge were age $(p$-value $<0.001)$, gender $(p-$ value 0.042 ), level of education ( $p$-value $<0.001$ ) and socioeconomic status (p-value 0.048). This result is shown in (Table 4$)$.

The presences of Multicollinearity within the set of independent variables were determined by using variance inflation factor (VIF). Here all value of independent variables variance inflation factors were less than ten so, there doesn't exist Multicollinearity between independents variables. This is shown in (Table 5).

Binary logistic regressions were used for statistically significant variables. Result shows the output of logistic regression for different characteristics. Students who were in the age group 20-25 years had 3.54 times (with 95\% CI for OR = 1.869 to 6.689) and who were in the age group 2530 years had 14.04 times (with $95 \%$ CI for OR = 5.292 to 37.262 ) good knowledge as compare to those who were in the age group 15-20 years. Female students had 2 times (with 95\% CI for OR $=1.002$ to 3.977 ) good knowledge as compare to female male students. Students who were from BDS had 0.83 times (with $95 \%$ CI for OR $=0.159$

\begin{tabular}{|c|c|c|c|c|}
\hline \multirow{3}{*}{$\begin{array}{l}\text { Characteristics } \\
\text { Age of the respondents }\end{array}$} & \multicolumn{2}{|c|}{ Level of Knowledge } & \multirow{3}{*}{ Chi- } & \multirow{2}{*}{ P- } \\
\hline & Good & Poor & & \\
\hline & & & & \\
\hline $15-20$ & $17(10)$ & $153(90)$ & & \\
\hline $20-25$ & $62(31.8)$ & $133(68.2)$ & 4805 & $<0.01 *$ \\
\hline \multicolumn{5}{|l|}{$\begin{array}{l}25-30 \\
\text { Gender }\end{array}$} \\
\hline Male & 19(15.7) & $102(84.2)$ & & \\
\hline Female & $79(28.8)$ & $195(71.2)$ & 7.75 & 0.042 \\
\hline \multicolumn{5}{|l|}{ Address } \\
\hline $\begin{array}{l}\text { Urban } \\
\text { Rural }\end{array}$ & $88(25.7)$ & $254(74.3)$ & & \\
\hline \multirow{2}{*}{\multicolumn{5}{|c|}{ Level of education }} \\
\hline & & & & \\
\hline BDS & $2(8)$ & $23(92)$ & & \\
\hline Nursing & $41(31.5)$ & $89(68.5)$ & & \\
\hline BPH & $30(46.2)$ & $35(53.8)$ & & $<0.001$ \\
\hline B Pharmacy & $17(20.7)$ & $65(79.3)$ & 36.64 & $*$ \\
\hline \multicolumn{5}{|l|}{ Religion } \\
\hline Hindu & $87(24.2)$ & $272(75.8)$ & & \\
\hline Buddhist & $7(28)$ & $18(72)$ & & \\
\hline Christian & $3(50)$ & $3(50)$ & & \\
\hline Muslim & $1(25)$ & $3(75)$ & & \\
\hline Others & & $1(100)$ & 2.57 & 0.63 \\
\hline \multicolumn{5}{|l|}{ Ethnicity } \\
\hline Brahmin & $50(24.3)$ & $156(75.7)$ & & \\
\hline Chhettri & $22(30.1)$ & $51(69.9)$ & & \\
\hline Dalit/Janajati/Gurung/Magar & $21(23.3)$ & $69(76.7)$ & & \\
\hline Others & $5(19.2)$ & $21(80.8)$ & 1.68 & 0.64 \\
\hline \multicolumn{5}{|l|}{ Socioeconomic status } \\
\hline Upper I & $8(12.1)$ & $58(87.9)$ & & \\
\hline Upper Middle class II & $69(28.6)$ & $172(71.4)$ & & \\
\hline Lower Middle class III & $18(25)$ & $54(75)$ & & \\
\hline Upper Lower class IV & $3(18.8)$ & $13(81.3)$ & 7.89 & $0.048^{*}$ \\
\hline
\end{tabular}

*Statistically significant at $5 \%$ level of significance. 
Upadhyay et al. Knowledge on National Free Health Services among Preclinical Medical..

\begin{tabular}{|c|c|c|c|c|c|c|c|}
\hline \multirow{2}{*}{ Variables (in Model) } & \multicolumn{2}{|c|}{ Unstandardized Coeffi- } & \multirow{2}{*}{$\begin{array}{c}\text { Standardized Coeff. } \\
\text { Beta }\end{array}$} & \multirow{2}{*}{$\mathrm{t}$} & \multirow{2}{*}{$\begin{array}{l}\mathrm{p}- \\
\text { value }\end{array}$} & \multicolumn{2}{|c|}{ Collinearity Statistics } \\
\hline & $\mathrm{B}$ & Std. Error & & & & Tolerance & VIF \\
\hline (Constant) & 0.732 & 0.131 & & 5.6 & 0.001 & & \\
\hline Age & 0.243 & 0.036 & 0.347 & 6.66 & 0.001 & 0.812 & 1.232 \\
\hline Gender & 0.116 & 0.045 & 0.123 & 2.57 & 0.01 & 0.96 & 1.042 \\
\hline Address & -0.089 & 0.062 & -0.07 & -1.42 & 0.155 & 0.916 & 1.091 \\
\hline Level of education & 0.005 & 0.016 & 0.018 & 0.331 & 0.741 & 0.781 & 1.28 \\
\hline Religion & 0.01 & 0.044 & 0.011 & 0.225 & 0.822 & 0.874 & 1.144 \\
\hline Ethnicity & -0.016 & 0.023 & -0.036 & -0.695 & 0.487 & 0.817 & 1.225 \\
\hline Socioeconomic status & 0.01 & 0.03 & 0.017 & 0.348 & 0.728 & 0.914 & 1.094 \\
\hline
\end{tabular}

to 4.319), students who were from Nursing had 1.70 times (with $95 \%$ CI for $\mathrm{OR}=0.658$ to 4.402 ), students who were from BPH had 4.34 times (with $95 \%$ CI for OR $=1.698$ to 11.087 ) and students who were from B Pharmacy had 1.10 times (with $95 \%$ CI for OR $=0.415$ to 2.941 ) times higher odds of knowledge as compare to those students who were from MBBS. And also in bi-variate analysis statistically significant they are age (p-value $<0.001$ ), gender ( $p$-value 0.049 ), level of education (p-value $<0.001)$. This result is shown in (Table 6). value. In logistic regression model indication of the amount of variation in the dependent variable is given by Cox \& Snell R-square and Nagelkerker R -square which are described as pseudo R-square. The results reveals that the value are 0.172 and 0.255 respectively suggesting that between $17.2 \%$ and $25.5 \%$ of the variation in response variable is explained by the set of independent variables used in the model and remaining variation is by other variable which are not included in the model (Table 8).

\begin{tabular}{|c|c|c|c|c|c|c|c|}
\hline \multirow{2}{*}{ Variable } & \multirow{2}{*}{ B } & \multirow{2}{*}{ S.E. } & \multirow{2}{*}{ Wald } & \multirow{2}{*}{ p-value } & \multirow{2}{*}{ OR } & \multicolumn{2}{|c|}{ 95\% C.I. for OR } \\
\hline & & & & & & Lower & Upper \\
\hline \multicolumn{8}{|l|}{ Age } \\
\hline \multicolumn{8}{|l|}{$15-20$ (ref) } \\
\hline $20-25$ & 1.263 & 0.325 & 15.082 & $<0.001$ & 3.54 & 1.869 & 6.689 \\
\hline $25-30$ & 2.642 & 0.498 & 28.155 & $<0.001$ & 14.04 & 5.292 & 37.262 \\
\hline \multicolumn{8}{|l|}{ Gender } \\
\hline \multicolumn{8}{|l|}{ Male (ref) } \\
\hline Female & 0.691 & 0.352 & 3.864 & 0.099 & 2 & 1.002 & 3.977 \\
\hline \multicolumn{8}{|c|}{ Level of education } \\
\hline \multicolumn{8}{|l|}{ MBBS (ref) } \\
\hline BDS & -0.188 & 0.843 & 0.05 & 0.082 & 0.83 & 0.159 & 4.319 \\
\hline Nursing & 0.532 & 0.485 & 1.201 & 0.027 & 1.7 & 0.658 & 4.402 \\
\hline $\mathrm{BPH}$ & 1.468 & 0.479 & 9.4 & 0.002 & 4.34 & 1.698 & 11.087 \\
\hline B Pharmacy & 0.099 & 0.5 & 0.039 & 0.084 & 1.1 & 0.415 & 2.941 \\
\hline Constant & -3.114 & 0.448 & 48.261 & 0 & 0.04 & & \\
\hline
\end{tabular}

In binary logistic regression Hosmer- Lemeshow test statistic was used for the model adequacy test. For this test a model is said to be poor fit if the pvalue is less than 0.05 . Here chi-square value is 2.559 with 3 degree of freedom and p-value is 0.465 , which implies that there is no significant difference between observed and predicted values indicating that model fit the data at an acceptable level (Table 7). Strength of logistic regression relationship is computed from the pseudo R-square

\begin{tabular}{|lcc|}
\hline \multicolumn{3}{|c|}{ Table 7. Model Adequacy Test. $(\mathbf{n}=\mathbf{3 9 5})$} \\
\hline \multicolumn{3}{|c|}{ Hosmer and Lemeshow Test } \\
Chi-square & df & P-value \\
2.559 & 3 & 0.465 \\
\hline
\end{tabular}

\begin{tabular}{|ccc|}
\hline $\begin{array}{l}\text { Table 8. } \\
(\mathbf{n}=\mathbf{3 9 5})\end{array}$ & Strength of Binary Logistic & Regression. \\
\hline \multicolumn{3}{|c|}{ Model Summary } \\
-2 Log likeli- & Cox \& Snell R & Nagelkerke R \\
hood & Square & Square \\
368.114 & 0.172 & 0.255 \\
\hline
\end{tabular}

\section{DISCUSSION}

Our research among 395 health sciences students showed the mean $\pm \mathrm{SD}$ was $21.44 \pm 2.44$ years, majority of students were female and urban by place of residence. The finding of this research showed that the range of age was 20-59 years and majority of them were female. ${ }^{3}$ Another study was conducted among health professionals showed that 
majority of them were female and majority were nurses. ${ }^{1}$ Our finding showed that nearly half $(42.03 \%)$ of the students know the meaning of free health services. The finding of NEAT and RECPHEC showed that only a half of poorest households had heard about free health care services compared to household heads from the wealthiest quintile and Dalits were less aware of free health care than other and regarding sources of information on free care, $91 \%$ of household heads possessing a radio or cassette player were aware, compared to only $65 \%$ who did not possess one. ${ }^{12}$ The study of Oladimeji $\mathrm{O}$ in South Africa showed that $52.4 \%$ of the respondents had knowledge of the National Health Insurance modalities while $44.6 \%$ did not know. ${ }^{3}$ This study found that illiterate and lower-caste people were more likely to choose the public health facilities. ${ }^{2}$ Only $11.39 \%$ of the students know the name of different health care program provided in Nepal and nearly one fourth $(23.04 \%)$ know the number of vaccine available at free of cost in Nepal. Only (6.90\%) students know the name of dangerous disease for which government has given some found for the treatment and more than $70 \%$ students know the amount of fund given by government for the treatments of disease. Also, one third (34.94\%) students know the number of medicine given free of cost in Government health institution.

Nearly half of the students know the amount that has to be deposited in National health insurance system and nearly $70 \%$ student knows the minimum distance of accessibility of basic health services to people. More than half of the students know the name of frontline volunteer of community to provide health services and linked community to the health institution. Very few $(4.30 \%)$ of the students know all the name of disease for which treatment is given free of cost by government of Nepal. Only one third (31.65\%) students know the name of clinic at health institution from where the medicine of tuberculosis is given. Also, $8.10 \%$ students know the component of safe Motherhood and Newborn health program. More than 75\% students know the incentive given to the mother when delivery is conducted on health institution.

Only $(7.79 \%)$ students know the activities comes under Nutrition program. More than $40 \%$ students know the name of health worker who support in home delivery and encourage applying Chlorhexidine to the umbilicus of new born child. Our finding showed that $24.8 \%$ students had good knowledge on national free health services with $95 \%$ confidence interval of good knowledge are $20.81 \%$ to $29.3 \%$. The level of knowledge was high among the students of young adult age (25-30 years) group and female students had good knowledge and students from urban area had good knowledge. In relation to level, BPH students had good knowledge followed by nursing students and least were in BDS students. Christian students had good knowledge and among Chhettri/Brahmin had good knowledge as compare to other caste. Students of upper middle class had good knowledge. People in the urban areas are more aware on national free health services as compare to rural areas people. ${ }^{10}$

Only $61.8 \%$ of the Nepalese households have access to health facilities within $30 \mathrm{~min}$, with significant urban (85.9\%) and rural (59\%) discrepancy. ${ }^{13}$ The statistically significant variables in bi-variate table were age ( $p$-value $<0.001$ ), gender (p-value 0.042), level of education (pvalue $<0.001)$ and socioeconomic status ( $p$-value 0.048). Ethnicity and low education status were significantly associated with choice of public health facilities. ${ }^{2}$ In order to find the net effect of all independents variable on dependent variable, VIF was calculate and value of independent were less than ten so, there doesn't exist Multicollinearity between independents variables.

Result in binary logistic regression showed that students who were in the age group 20-25 years had 3.54 times (with 95\% CI for OR $=1.869$ to 6.689 ) as compare to those who were in the age group 1520 years and students of age 25-30 years had 14.04 times (with $95 \% \mathrm{CI}$ for OR $=5.292$ to 37.262 ) good knowledge as compare to those who were in the age group 15-20 years. Female students had 2 times (with $95 \%$ CI for OR $=1.002$ to 3.977 ) good knowledge as compare to female male students. Students who were from BDS had 0.83 times (with $95 \%$ CI for OR $=0.159$ to 4.319 ), students who were from Nursing had 1.70 times (with $95 \%$ CI for $\mathrm{OR}=0.658$ to 4.402 ), students who were from $\mathrm{BPH}$ had 4.34 times (with $95 \% \mathrm{CI}$ for $\mathrm{OR}=1.698$ to 11.087) and students who were from B Pharmacy had 1.10 times (with $95 \%$ CI for OR $=0.415$ to 2.941) times higher odds of knowledge as compare to those students who were from MBBS. HosmerLemeshow p-value is 0.465 , which implies that model fit the data at an acceptable level. In order to find the indication of the amount of variation in the dependent variable Cox \& Snell R-square and Nagelkerker R-square was calculate which are described as pseudo R-square, the results reveals that the value are 0.172 and 0.255 respectively suggesting that between $17.2 \%$ and $25.5 \%$ of the variation in response variable (level of knowledge) is explained by the set of independent variables used in the model and remaining variation is by other variable which are not included in the model.

\section{CONCLUSIONS}

The overall level of knowledge among the health sciences students is poor; only one fourth students 
had good level of knowledge. Majority of the students don't know name of the basic free health services provided by government of Nepal. Students of younger adult had good knowledge. BPH and Nursing students had good knowledge as compared to other level. Statistically significant variable with level of knowledge are age (p-value $<0.001$ ), gender (p-value 0.049), level of education (p-value $<0.001)$.

\section{REFERENCES}

1. Borghi J, Ensor T, Neupane BD, Tiwari S. Financial implications of skilled attendance at delivery in Nepal. Tropical Medicine \& International Health. 2006;11(2):228-37.

2. Karkee R, Kadariya J. Choice of health-care facility after introduction of free essential health services in Nepal. WHO South-East Asia Journal of Public Health. 2013;2(2):96.

3. Setswe G, Muyanga S, Witthuhn J, Nyasulu P. Public awareness and knowledge of the National Health Insurance in South Africa. Pan African Medical Journal. 2015;22(1).

4. MoHP. Free Health Care in Nepal, Findings of a Rapid Assessment:. November 2009 .

5. Khanal P. Right to Health in Nepal: Commitment versus Challenges. Health for All. 2014;2(1):3-5.

6. Witter S, Khadka S, Nath H, Tiwari S. The national free delivery policy in Nepal. Health Policy and Planning. 2011;26(suppl_2).

7. DoHS. Glimpse of Annual Report. 2016/2017.

8. Prasai DP. A review of studies on Nepal's national free health care programme. Kathmandu: Primary Health Care Revitalization

\section{ACKNOWLEDGEMENTS}

We are thankful to all MBBS, BDS, BPH, B. Pharmacy and B. Nursing students of College of Medical Sciences and Shree Medical \& Technical College of Bharatpur, Chitwan for their valuable support and time during data collection.

\section{Conflict of Interest: None}

Division, Department of Health Services, Ministry of Health and Population (GoN). 2013.

9. More people benefitting from govt's free health services. The Himalayan Times May-30, 2019.

10. Gurung G. Free Health Care Policy in Nepal: Recent Trend and Challenges. Journal of Nepal Health Research Council. 2009;7(2):138-9.

11. Oladimeji O, Alabi A, Adeniyi OV. Awareness, Knowledge and Perception of The National Health Insurance Scheme (NHIS) Among Health Professionals in Mthatha General Hospital, Eastern Cape, South Africa. The Open Public Health Journal. 2017;10(1).

12. RECPHEC Na. Field Study on Essential Health Care and Free Maternity Services in Nepal Final Study Report. 2011.

13. CBS. Nepal Living Standards Survey 2010/11. Kathmandu, Nepal: 2010/11.

14. Assessment of Social Health Insurance scheme in selected districts of Nepal. Kathmandu, Nepal: Nepal Health Research Council, 2018

15. Ministry of Health and Population, National Immunization Programme Kathmandu, Nepal: 2019.

Citation: Upadhyay HP, Prasai N, Prasai M, Sedai P, Panthi S. Knowledge on National Free Health Services among Preclinical Medical Students. JCMS Nepal. 2019; 15(3):179-85. 